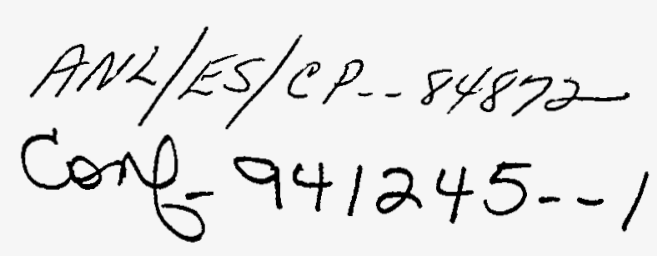

\title{
CHELANT EXTRACTION AND REDOX MANIPULATION FOR MOBILIZATION OF HEAVY METALS FROM CONTAMINATED SOILS
}

\author{
Michael D. Brewster, Robert W. Peters, Gregory A. Miller, \\ Terry L. Patton, and Louis E. Martino \\ Argonne National Laboratory \\ 9700 South Cass Avenue \\ Argonne, Illinois 60439
}

\begin{abstract}
As the result of open burning and open detonation of chemical agents and munitions in the Toxic Burning Pits area at J-Field, located in the Edgewood Area of Aberdeen Proving Ground in Harford County, Maryland, soils have been contaminated with heavy metals. Simultaneous extraction is complicated because of the multitude of contaminant forms (e.g., soluble, insoluble, ionic, complexed, adsorbed, organometallic, etc.) that exist. This paper uses data from a treatability study performed at Argonne National Laboratory to discuss and compare several treatment methods that were evaluated for remediating metals-contaminated soils. J-Field soils were subjected to a series of treatability experiments designed to determine the feasibility of using soil washing/soil flushing, enhancements to soil washing/soil flushing, solidification/stabilization, and electrokinetics for remediating soils contaminated with metals. Chelating and mobilizing agents evaluated included ammonium acetate, ethylenediaminetetraacetic acid, citric acid, Citranox, gluconic acid, phosphoric acid, oxalic acid, and nitrilotriacetic acid, in addition to $\mathrm{pH}$-adjusted water. REDOX manipulation can maximize solubilities, increase desorption, and promote removal of heavy metal contaminants. Reducing agents that were studied included sodium borohydride, sodium metabisulfite, and thiourea dioxide. The oxidants studied included hydrogen peroxide, sodium percarbonate, sodium hypochlorite, and potassium permanganate. This paper summarizes the results (received to date) from the physical/chemical characterization, soil washing/soil flushing, and enhancements to soil washing/soil flushing portions of the study.
\end{abstract}

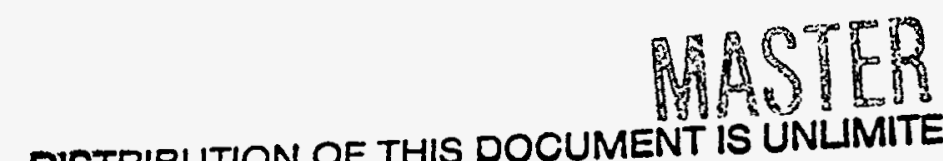

DISTRIBUTION OF THIS DOCUMENT IS UNLIMITED

DISCLAIMER

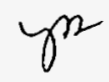

\begin{abstract}
This report was prepared as an account of work sponsored by an agency of the United States Government. Neither the United States Government nor any agency thereof, nor any of their employees, makes any warranty, express or implied, or assumes any legal liability or responsibility for the accuracy, completeness, or usefulness of any information, apparatus, product, or process disclosed, or represents that its use would not infringe privately owned rights. Reference herein to any specific commercial product, process, or service by trade name, trademark, manufacturer, or otherwise does not necessarily constitute or imply its endorsement, recommendation, or favoring by the United States Government or any agency thereof. The views and opinions of authors expressed herein do not necessarily state or reflect those of the United States Government or any agency thereof.
\end{abstract}




\section{DISCLAIMER}

Portions of this document may be illegible in electronic image products. Images are produced from the best available original document. 


\section{CHELANT EXTRACTION AND REDOX MANIPULATION FOR MOBILIZATION OF HEAVY METALS FROM CONTAMINATED SOILS}

\section{INTRODUCTION}

J-Field, located in the Edgewood Area of Aberdeen Proving Ground in Harford County, Maryland, has contaminated soils as a result of past disposal activities, which included the open burning and open detonation of chemical agents and munitions. The Toxic Burning Pit (TBP) area at J-Field consists of five disposal pits used for open burning and open detonation. Two of these pits, known as the primary burning pits, are the subject of a focused feasibility study (FFS) being performed at Argonne National Laboratory.

The purpose of the FFS is to develop and evaluate alternative remedial actions to address contamination in the TBP area at J-Field. The soils in the primary burning pits are contaminated mainly with volatile organic compounds, including 1,2-dichloroethene (up to $8,400 \mu \mathrm{g} / \mathrm{kg}$ ), trichloroethene (up to $21,000 \mu \mathrm{g} / \mathrm{kg}$ ), 1,1,2-trichloroethane (up to $1,600 \mu \mathrm{g} / \mathrm{kg}$ ), and 1,1,2,2tetrachloroethane (up to $220,000 \mu \mathrm{g} / \mathrm{kg}$ ). To the east of these pits, where material was pushed out into the adjacent marsh, soils are predominantly contaminated with heavy metals, including arsenic (up to $41 \mathrm{mg} / \mathrm{kg}$ ), copper (up to $4,320 \mathrm{mg} / \mathrm{kg}$ ), lead (up to $94,200 \mathrm{mg} / \mathrm{kg}$ ), antimony (up to 501 $\mathrm{mg} / \mathrm{kg}$ ), and zinc (up to $6,690 \mathrm{mg} / \mathrm{kg}$ ).

The FFS was designed to evaluate several proposed treatment methods for remediating metals-contaminated soils in the push-out area: soil washing, soil flushing, enhancements to soil washing and soil flushing, stabilization/solidification, and electrokinetics. Argonne has completed several project tasks of the FFS. This paper summarizes the results (received to date) from the physical/chemical soil characterization, soil washing/soil flushing, and enhancements to soil washing/soil flushing portions of the study. On the basis of their concentrations in the untreated TBP soils and degree of environmental impact, the primary heavy metals of concern for the FFS were copper, lead, and zinc.

\section{PROCEDURES AND EQUIPMENT}

The tasks performed in the FFS include (1) physical and chemical soil characterization, (2) soil washing/soil flushing, (3) enhancements to soil washing and soil flushing, (4) solidification/stabilization, and (5) electrokinetic treatment. Detailed descriptions of the tasks performed in this project are given below.

\section{Task 1: Physical and Chemical Soil Characterization}

Soil samples (background, representative, and worst-case) used in the study were composited over a depth interval of $4 \mathrm{ft}$. Before being shipped to Argonne, all samples were screened and found to be free of agent materials. Physical and chemical analyses were performed to characterize the soil. Characterization analyses included total extractable metals, toxicity characteristic leaching procedure (TCLP) for metals only, cation exchange capacity, soil $\mathrm{pH}$, metal speciation via sequential extraction, moisture content, color, bulk density, soil texture, and particle size analysis. The characterization analyses are summarized in Table 1. 
Table 1: Methods for Soil Characterization

\begin{tabular}{ll}
\hline Soil Parameter & Method \\
\hline Total extractable metals & U.S. Environmental Protection Agency \\
& (EPA) 3050A \\
TCLP analyses (metals only) & EPA, 40 CFR, Part 261 \\
Cation exchange capacity & EPA 9081 \\
Soil pH & EPA 9045 \\
Metal speciation via sequential extraction & U.S. Army Corps of Engineers \\
Moisture content (total residue) & Standard Methods 209A \\
Color & Munsell Soil Color Charts \\
Bulk density (SARAN method) & EPA-600/2-78-0-54 \\
Soil texture (hydrometer, 2 h) & EPA-600/2-78-0-54 \\
Particle size distribution & American Society for Testing and \\
& Materials, D 422 \\
Oxidation/reduction potential (ORP) & Standard Methods 2580
\end{tabular}

\section{Task 2: Soil Washing/Soil Flushing}

Soils contaminated with heavy metals, primarily lead, were subjected to a series of batchshaker flask experiments to identify the chelating agents and surfactants that show promise in mobilizing lead and other metals from the TBP soils. Chelating and mobilizing agents evaluated included ethylenediamine-tetraacetic acid (EDTA), citric acid, Citranox, gluconic acid, phosphoric acid, oxalic acid, nitrilotriacetic acid (NTA), and ammonium acetate, in addition to $\mathrm{pH}$-adjusted water. Soil washing experiments were performed by first placing nominal 5-g portions of TBP soils in plastic shaker containers. To these containers, $45-\mathrm{mL}$ of extractant solution $(0.01 \mathrm{M}$, $0.05 \mathrm{M}$, or $0.1 \mathrm{M}$ ) were added. Contact time was maintained at $3 \mathrm{~h}$; preliminary experiments indicated that this contact time was sufficient to achieve pseudo-equilibrium conditions. After the required contact time, solid/liquid separation was done by vacuum filtration. The filtrates collected were analyzed for copper, lead, and zinc by atomic absorption spectrophotometry.

Soil flushing experiments were performed in aluminum columns with fixed glass walls. The columns were hand-packed, and the weight of soil contained in the columns was measured. The columns were operated by an upflow leaching technique. The volumes of solution needed to saturate the soils initially were noted and assumed to approximate one pore volume. Columns containing contaminated TBP soils were flooded with wash solutions while operating in an upflow mode. Individual extractant solutions contained one chelant at a concentration determined as optimum from the results of the batch-shaker tests. Data collected included the following: columnar solution feed flow rates, operating temperature, extractant type and concentration, $\mathrm{pH}$ (before and after treatment), metals removal efficiency, and pore volumes applied.

\section{Task 3: Enhancements to Soil Washing/Soil Flushing}

Another set of experiments was aimed at improving the performance of soil washing/soil flushing by pretreating the soils before performing soil washing/soil flushing operations. The Argonne researchers investigated the use of sonication and REDOX manipulation to increase the removal of heavy metals from the TBP soils. Sonication involves the application of high-energy sound waves to degrade organic pollutants and enhance the removal of heavy metals from the soils. A laboratory-scale apparatus (Sonics \& Materials, VC 600) was used for the sonication treatment. Variables investigated included input power, operation temperature, $\mathrm{pH}$, and addition of chemical enhancements. 
The sonication-enhanced soil washing experiments were performed by first placing nominal 5-g portions of TBP soils in 50-mL plastic centrifuge tubes. After $25 \mathrm{~mL}$ of deionized water was added to each centrifuge tube, the samples were subjected to sonication for 10 minutes. Then, the lids to the centrifuge tubes were replaced, and the tubes were centrifuged to separate the solid and liquid phases. Aliquots $(5 \mathrm{~mL})$ were collected and analyzed for metals by atomic absorption spectrophotometry. To the solutions remaining in the centrifuge tubes, $25 \mathrm{~mL}$ of the $0.05 \mathrm{M}$ chelants (citric acid or EDTA) was added. The extractant solutions were $\mathrm{pH}$ adjusted (pH 5, pH 9) before being added to the sonication-treated TBP soils. Standard batch-shaker soil washing tests were performed on the samples to determine the effect of sonication on heavy metal extraction by soil washing.

REDOX manipulation can provide conditions that maximize the solubilities of contaminants and promote their removal. Reducing agents studied included sodium borohydride, sodium metabisulfite, and thiourea dioxide. For some soils and heavy metals, oxidizing agents may enhance metals removal by degrading organometallic complexes and releasing metals that have an affinity for natural organic matter. Hydrogen peroxide, sodium percarbonate, sodium hypochlorite, and potassium permanganate were the oxidants evaluated for REDOX manipulation. The oxidizing and reducing agents used were chosen on the basis of their REDOX characteristics, operating conditions (e.g., $\mathrm{pH}$, concentration, etc.), ionic content, and availability.

The oxidizing and reducing agents used for REDOX modification were screened by adding $45-\mathrm{mL}$ aliquots of $1000-\mathrm{ppm}$ solutions of each reagent to nominal $5-\mathrm{g}$ portions of the representative TBP soils. The soil samples were then processed in a manner similar to the batchshaker flask soil washing method used in task 2. Variables monitored to determine the effect of REDOX manipulation included $\mathrm{pH}$, ORP, and metals removal efficiencies. As the result of the screening tests, sodium borohydride (highest change in ORP), sodium metabisulfite (most common and versatile of the reducing agents studied), and sodium percarbonate (highest lead removal of the oxidants studied) would be used to enhance heavy metal extraction by treating the TBP soils with the REDOX modifiers before performing the chelant extraction procedures.

REDOX modification was combined with chelant extraction to extract copper, lead, and zinc from the representative TBP soil sample. Aliquots $(45 \mathrm{~mL})$ of the $1000-\mathrm{ppm}$ solutions of the oxidizing and reducing agents were combined with nominal 5-g portions of the TBP soils. After the required contact time, solid/liquid separation was performed by vacuum filtration. To the residual soils, $45 \mathrm{~mL}$ of the $0.05 \mathrm{M}$ chelant (EDTA, citric acid) solutions was added. The chelant extraction step was done according to the soil washing procedure described earlier in task 2 . Variables measured in the intermediate (following REDOX manipulation) and final (after chelant extraction) samples to quantify and explain the combined REDOX modification/chelant extraction approach included $\mathrm{pH}$, ORP, copper, lead, and zinc.

\section{Task 4: Solidification/Stabilization}

Future solidification/stabilization experiments will use the untreated soil, the heavy-metalladen sludges (resulting from metals removal and extractant treatment), and the residual soil after soil washing/soil flushing treatment. The stabilizing agent to be considered is portland cement. The contaminated sludges are incorporated into the solidification/stabilization matrix to minimize the leaching potential of lead and other heavy metals from the solidified matrix. The effectiveness of this process technique will be determined on the basis of TCLP testing.

\section{Task 5: Electrokinetic Treatment}

The use of electrokinetics for soil remediation involves the application of an electric potential to electrodes that have been placed in the ground. The electric potential causes reactions to occur at the corresponding electrodes and promotes contaminant transport through two main mechanisms: electromigration and electroosmosis. REDOX reactions occur at the electrodes and result in the hydrolysis of water. Oxygen gas and hydrogen ions are produced by oxidation at the 
anode. Reduction at the cathode produces hydrogen gas and hydroxyl ions. For a given amount of electrical input, twice as many water molecules are broken down at the cathode as at the anode. This process provides a gradient for water transport and contributes to electroosmosis.

In in situ electroosmosis, water containing hydrogen ions and other cations moves from the anode toward the cathode. As this acid front moves, it carries and concentrates contaminants. Electromigration is the transport of charged ions through a solution. Cations migrate toward the cathode, while anions are attracted toward the anode. Thus, an electric field can be used to move ionic contaminants even if the liquid phase is stationary.

Task 5 will investigate the use of electrokinetics by applying various treatment operating conditions (e.g., voltages, currents, flow rates, $\mathrm{pH}$, chemical enhancements, etc.) in order to mobilize lead from the soil effectively. A direct current power supply will be operated at current densities below $1 \mathrm{~mA} / \mathrm{cm}^{2}$ and voltages less than $3 \mathrm{~V}$. Direction, extent, and rate of lead movement will be determined. In this task, lead-contaminated soil is placed in the middle compartment of the experimental apparatus. The remaining compartments are filled with noncontaminated soil. After the electrokinetic test apparatus is operated for given amounts of time and under various operating conditions, soil and liquid samples are collected from the sampling ports/compartments. The direction and rate of heavy metal transport is determined. When chemical enhancements are combined with electrokinetics, the rate and direction of transport may be altered. A thorough sampling plan will be used to identify how and to what extent lead removal occurs when enhanced electrokinetic soil remediation is implemented.

\section{RESULTS AND DISCUSSION}

\section{Task 1: Physical/Chemical Soil Characterization}

The TBP soils (worst-case, representative, and background) have the following characteristics: all are generally brownish in color, have a low cation exchange capacity $(1.2-4.0 \mathrm{meq} / 100 \mathrm{~g})$, are slightly alkaline ( $\mathrm{pH}$ range of 7.5-8.4), have a moderate volatile solids content (2.5-8.8\%), and are of a sandy loam texture. The particle size distribution determined from hydrometer tests indicated that the soil consisted of approximately $60 \%$ sand, $30 \%$ silt, and $10 \%$ clay. Table 2 summarizes the total extractable metals concentrations of these soils. The results for the TCLP tests performed on the untreated soils are summarized in Table 3 . The representative and worst-case samples were very similar in heavy metal content. They were distinguished by the concentration of lead. Lead was the primary contaminant of concern because it was the only metal that leached appreciably from the representative and worst-case samples and caused the respective samples to fail the TCLP tests.

Table 2: Total Extractable Metals (mg/kg)

\begin{tabular}{crrr}
\hline Heavy Metal & \multicolumn{1}{c}{$\begin{array}{l}\text { Worst-Case } \\
\text { Sample }\end{array}$} & $\begin{array}{l}\text { Representative } \\
\text { Sample }\end{array}$ & $\begin{array}{c}\text { Background } \\
\text { Sample }\end{array}$ \\
\hline & & & 9.5 \\
$\mathrm{As}$ & 17.8 & 21.8 & 2.2 \\
$\mathrm{Cd}$ & 7.4 & 6.6 & 38.7 \\
$\mathrm{Cr}$ & 238.7 & 311.7 & 88.4 \\
$\mathrm{Cu}$ & $1,241.3$ & $1,533.2$ & $10,913.3$ \\
$\mathrm{Fe}$ & $39,858.0$ & $48,312.3$ & 1.6 \\
$\mathrm{Hg}$ & 1.6 & 1.4 & 92.7 \\
$\mathrm{Mn}$ & 203.5 & 286.3 & 4.0 \\
$\mathrm{Ni}$ & 27.7 & 35.7 & 58.9 \\
$\mathrm{~Pb}$ & $\mathbf{2 1 , 5 6 0 . 4}$ & $\mathbf{1 5 , 2 9 4 . 1}$ & 64.7 \\
$\mathrm{Zn}$ & $3,729.0$ & $3,677.0$ & \\
\hline
\end{tabular}


Table 3: TCLP Results (mg/L)

\begin{tabular}{crrrr}
\hline Heavy Metal & $\begin{array}{c}\text { Worst-Case } \\
\text { Sample }\end{array}$ & $\begin{array}{c}\text { Representative } \\
\text { Sample }\end{array}$ & $\begin{array}{c}\text { Background } \\
\text { Sample }\end{array}$ & $\begin{array}{c}\text { Regulatory } \\
\text { Level }\end{array}$ \\
\hline $\mathrm{As}$ & 0.023 & 0.025 & 0.038 & 5.0 \\
$\mathrm{Cd}$ & 0.09 & 0.09 & 0.02 & 1.0 \\
$\mathrm{Cr}$ & $<0.01$ & $<0.01$ & $<0.01$ & 5.0 \\
$\mathrm{Cu}$ & 5.57 & 6.86 & 0.22 & - \\
$\mathrm{Fe}$ & 0.01 & 0.18 & 0.13 & - \\
$\mathrm{Hg}$ & $\mathrm{NA}$ & $\mathrm{NA}$ & $\mathrm{NA}$ & 0.2 \\
$\mathrm{Mn}$ & 1.31 & 3.96 & 0.52 & - \\
$\mathrm{Ni}$ & $<0.1$ & $<0.1$ & $<0.1$ & - \\
$\mathrm{Pb}$ & $\mathbf{2 3 0 . 6 3}$ & $\mathbf{1 1 3 . 2 3}$ & 0.48 & $\mathbf{5 . 0}$ \\
$\mathrm{Zn}$ & 57.99 & 46.18 & 0.31 & - \\
\hline
\end{tabular}

Sequential extractions were performed on the worst-case and representative soils to determine the speciation of the metals forms. This technique speciates the heavy metal distribution into exchangeable forms, carbonates, reducible oxides, organically bound fractions, and residual forms. The reagents used in the sequential extraction process provide conditions (e.g., desorption, $\mathrm{pH}, \mathrm{REDOX}$, etc.) for maximum heavy metal extraction. The reagents and conditions used in the heavy metal speciation via sequential extraction procedure are listed in Table 4. It may be possible, depending on the volume of soil requiring treatment, to adapt portions of the sequential extraction procedure to remediating the TBP soils.

Table 4: Sequential Extraction Reagents and Conditions

\begin{tabular}{ll}
\hline Species & Reagents and Conditions \\
Exchangeable & $1 \mathrm{M}$ magnesium chloride for $60 \mathrm{~min}$ \\
Carbonate & $1 \mathrm{M}$ acetate buffer $(\mathrm{pH}=5)$ for $5 \mathrm{~h}$ \\
Reducible Oxides & $\begin{array}{l}0.04 \mathrm{M} \text { hydroxylamine hydrochloride in } 25 \% \text { acetic } \\
\text { acid at } 96^{\circ} \mathrm{C} \text { for } 6 \mathrm{~h}\end{array}$ \\
& $\begin{array}{l}30 \% \text { hydrogen peroxide and } 0.02 \mathrm{M} \text { nitric acid at } \\
85^{\circ} \mathrm{C} \text { for } 2 \mathrm{~h} \text { followed by extraction with } 3.2 \mathrm{M} \\
\text { ammonium acetate in } 20 \% \text { nitric acid }\end{array}$ \\
Organic & concentrated nitric acid at $95^{\circ} \mathrm{C}$ for $8 \mathrm{~h}$ \\
\hline
\end{tabular}

The heavy metals analyzed for were cadmium, copper, chromium, lead, zinc, manganese, and iron. Speciation of calcium, another important parameter, was also determined. Table 5 and Figure 1 provide summarized distributions of the heavy metals in the representative TBP soil samples. The data indicates that significant fractions of the metals are present as species (i.e., exchangeable + carbonate + reducible oxides) that are amenable to soil washing techniques. Calcium, cadmium, copper, lead, manganese, zinc, and chromium have more than $60 \%$ of their distribution in forms that are amenable to soil washing. Iron is somewhat less responsive to soil washing by chelant extraction or other methods of heavy metal mobilization and removal. 
The exchangeable and carbonate fractions are easily extracted by using chelants or other heavy metal mobilizing agents. Removal of metals present as reducible oxides greatly depends on the extracting agent used. The heavy metals present as organic and residual species are difficult to extract by soil washing, soil flushing, enhanced soil washing/soil flushing, and other soil remediation techniques. By speciating and quantifying the heavy metals present in contaminated soils, it is possible to predict heavy metal removal efficiencies and establish realistic, site-specific cleanup levels for the target heavy metals.

Table 5: Heavy Metal Speciation by Sequential Extraction (\%)

\begin{tabular}{llllll}
\hline \multirow{2}{*}{ Heavy Metal } & \multicolumn{5}{c}{ Species Classification } \\
\cline { 2 - 6 } & Exchangeable & Carbonate & Red. Oxides & Organic & Residual \\
$\mathrm{Ca}$ & 50.5 & 39.5 & 5.4 & 1.8 & 2.8 \\
$\mathrm{Cd}$ & 34.3 & 29.7 & 13.2 & 9.5 & 13.2 \\
$\mathrm{Cr}$ & 5.3 & 15.3 & 41.6 & 16.2 & 21.7 \\
$\mathrm{Cu}$ & 1.2 & 41.3 & 31.3 & 21.9 & 4.4 \\
$\mathrm{Fe}$ & 0.3 & 1.2 & 30.1 & 36.6 & 31.8 \\
$\mathrm{Mn}$ & 14.6 & 21.5 & 22.8 & 10.6 & 30.6 \\
$\mathrm{~Pb}$ & 1.7 & 26.8 & 28.9 & 14.7 & 27.9 \\
$\mathrm{Zn}$ & 3.3 & 44.5 & 28.1 & 10.4 & 13.7 \\
\hline
\end{tabular}

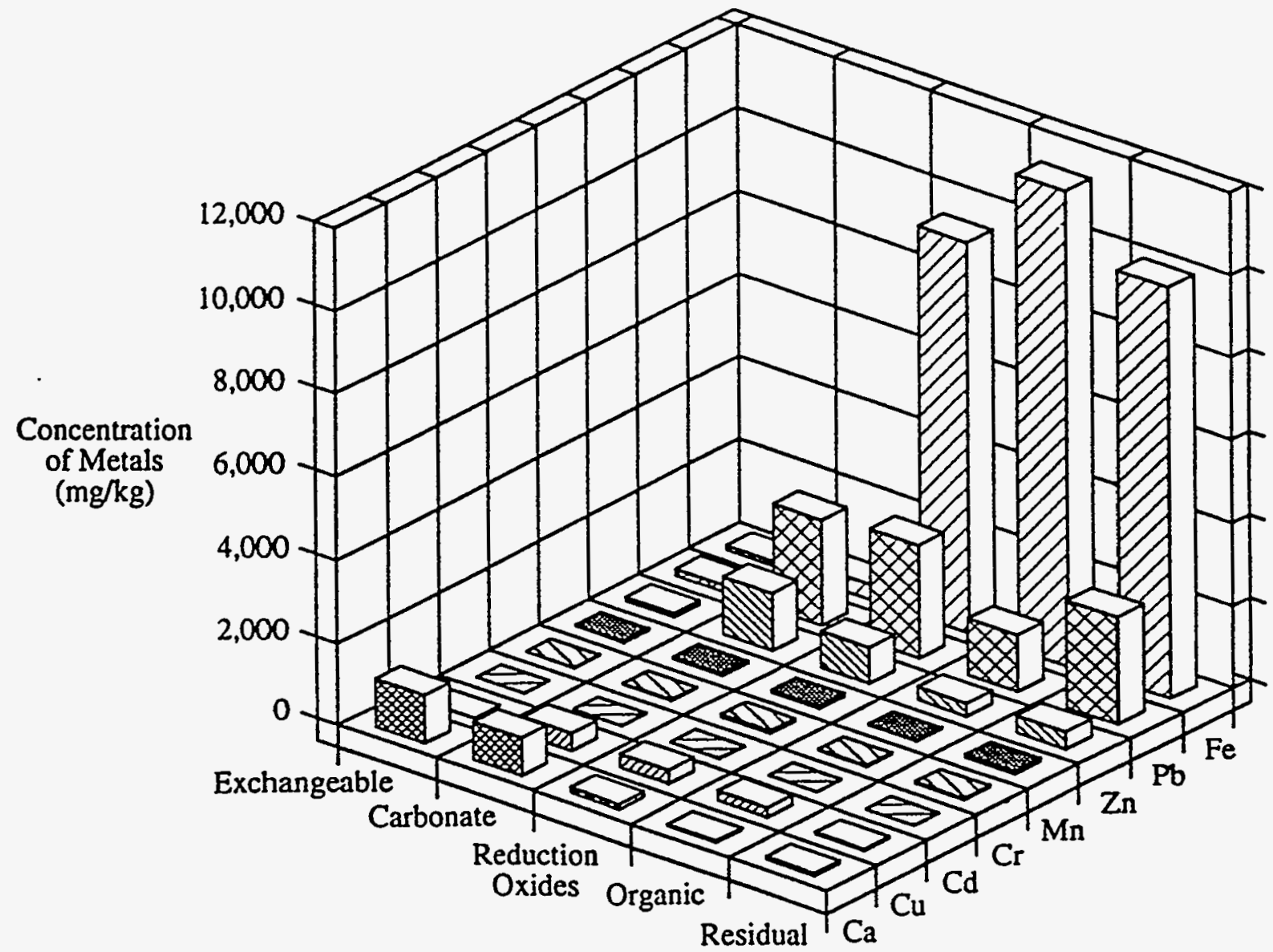

Figure 1: Sequential Extraction Results for Untreated Representative Soil Sample 


\section{Task 2: Soil Washing/Soil Flushing}

Because the worst-case and representative samples were very similar in heavy metal content and treatability, only the results of the soil washing, soil flushing, and enhancements to soil washing/soil flushing experiments performed on the representative sample are discussed here. The three heavy metal contaminants (copper, lead and zinc) present at the highest concentrations in the representative sample were analyzed for in the extractant solutions. The results were used to determine the feasibility of using soil washing and soil flushing techniques for remediating the TBP soils. At press time, most of the results from the soil washing/soil flushing, and enhancements to soil washing/soil flushing treatability tests have been received from Argonne's analytical laboratory. Results of the soil washing/soil flushing tests with the batch-shaker flask and column flooding techniques are summarized in Table 6. The trends listed in Tables 7 and 8 were indicated by the results from the soil washing/chelant extraction treatability tests.

Table 6: Chelant Extraction Results

\begin{tabular}{lccc}
\hline & \multicolumn{3}{c}{ Maximum Removal (\%) } \\
\cline { 2 - 4 } Extractant $(0.05 \mathrm{M})$ & & Lead & Zinc \\
\hline Citric acid & 35.9 & 5.2 & 19.9 \\
EDTA & 53.3 & 42.8 & 44.5 \\
Gluconic acid & 25.5 & 12.5 & 44.0 \\
NTA & 41.3 & 78.0 & 50.4 \\
Oxalic acid & 20.8 & 0.7 & 49.7 \\
Phosphoric acid & 1.3 & 0.04 & 8.4 \\
pH-adjusted water & 0.2 & 0.5 & 0.2 \\
\hline
\end{tabular}

Table 7: Chelant Extraction Efficiency

\begin{tabular}{ll}
\hline Metal & Chelant Extraction Efficiency \\
$\mathrm{Pb}$ & NTA $>$ EDTA $>>$ gluconic acid $>$ citric acid \\
& $>$ oxalic acid $>$ water $>$ phosphoric acid \\
$\mathrm{Cu}$ & EDTA $\gg$ NTA $>>$ citric acid $>$ gluconic acid \\
& $>$ oxalic acid $\gg>$ phosphoric acid $>$ water \\
$\mathrm{Zn}$ & NTA $\sim$ oxalic acid $\sim$ EDTA $\sim$ gluconic acid \\
& $>$ citric acid $\gg>$ phosphoric acid $>$ water \\
\hline
\end{tabular}

Table 8: Effectiveness of Heavy Metal Removal

\begin{tabular}{ll}
\hline Chelant & Effectiveness of Heavy Metal Removal \\
\hline Citric acid & $\mathrm{Cu}>>\mathrm{Zn}>>\mathrm{Pb}$ \\
EDTA & $\mathrm{Cu}>\mathrm{Zn} \sim \mathrm{Pb}$ \\
Gluconic acid & $\mathrm{Zn}>\mathrm{Cu}>\mathrm{Pb}$ \\
NTA & $\mathrm{Pb}>>\mathrm{Zn}>\mathrm{Cu}$ \\
Oxalic acid & $\mathrm{Zn}>>\mathrm{Cu}>>\mathrm{Pb}$ \\
Phosphoric acid & $\mathrm{Zn}>\mathrm{Cu} \sim \mathrm{Pb}$ \\
pH-adjusted water & Minimal effect, $\mathrm{Pb} \sim \mathrm{Cu} \sim \mathrm{Zn}$
\end{tabular}


The results generally indicate that slightly acidic conditions ( $\mathrm{pH} 4-6)$ result in greater removals of copper, lead, and zinc. The stronger chelants, EDTA and NTA, were less affected by the $\mathrm{pH}$. Because the weaker chelants rely more on other removal mechanisms (e.g., solubilization, desorption), the $\mathrm{pH}$ effect was more highly pronounced. Acids that provided an anion (i.e., oxalate, phosphate) and resulted in the formation of heavy metal precipitates were used in this study. Poor heavy metal extraction resulted when oxalic acid and phosphoric acid were used. This result was attributed to the precipitation of copper, lead, and zinc salts. Oxalic acid and phosphoric acid were included in the test plan because heavy metal contaminants existing as anions (i.e., arsenic as arsenate) were expected to be present in the TBP soils. Oxalate and phosphate can remove anionic forms of contaminants by competitively desorbing anions from adsorption sites on the surfaces of the soil particles.

When the heavy metal speciation via sequential extraction results are compared with the heavy metal removal efficiencies achieved by chelant extraction, the data indicate that soil washing and soil flushing are effective in removing the exchangeable and carbonate fractions of copper, lead, and zinc from the TBP soils. Removal of the reducible oxides fraction depends on the type of chelant used and the solubility of the individual oxides present. Table 9 identifies the relationship between the metals removal efficiencies and the quantities of metal present as exchangeable and carbonate species. Because Table 9 is provided mainly for discussion purposes, the list of chelants has been condensed to include only citric acid, EDTA, gluconic acid, and NTA.

To increase heavy metal extraction efficiencies, it is necessary to convert reducible oxides, organometallics, and residual species of heavy metals to exchangeable and carbonate forms. Heavy metals present as reducible oxides, organometallics, and residual forms are difficult to remove. Because of their reduced leachability, it may be acceptable to leave reducible oxides, organometallics, and other heavy metal residuals in the soils. Experiments are being performed to determine whether the soils treated by chelant extraction will pass TCLP tests. At press time, the TCLP results were not available.

Table 9: Relationship Between Metal Speciation and Chelant Extraction Efficiency

\begin{tabular}{|c|c|c|c|c|c|c|}
\hline \multicolumn{3}{|c|}{ Exchangeable + Carbonate (\%) } & \multirow[b]{2}{*}{ Chelant } & \multicolumn{3}{|c|}{$\operatorname{Removal}(\%)$} \\
\hline Copper & Lead & Zinc & & Copper & Lead & Zinc \\
\hline 42.5 & 28.5 & 47.8 & Citric acid & 35.9 & 5.2 & 19.9 \\
\hline 42.5 & 28.5 & 47.8 & EDTA & 53.3 & 42.8 & 44.5 \\
\hline 42.5 & 28.5 & 47.8 & Gluconic acid & 25.5 & 12.5 & 44.0 \\
\hline 42.5 & 28.5 & 47.8 & NTA & 41.3 & 78.0 & 50.4 \\
\hline
\end{tabular}

\section{Task 3: Enhancements to Soil Washing/Soil Flushing}

The use of sonication to enhance the extraction of copper, lead, and zinc from the TBP soils was investigated. The results of the treatability tests indicated that the use of sonication to pretreat the TBP soils before soil washing with chelants had very little effect on heavy metal extraction efficiencies. It was concluded that the application of high-energy sound waves was not a viable technique for increasing the chelant extraction rate of copper, lead, and zinc from the TBP soils. 
The results provided in Table 10 indicate that lead and copper removal by chelant extraction with EDTA and citric acid is minimally affected by pretreatment with sodium borohydride, sodium metabisulfite, and sodium percarbonate. Zinc removal by the stronger chelant, EDTA, was slightly increased by each REDOX agent studied. The reagents used for REDOX manipulation significantly improved the performance of citric acid for removing zinc from the worst-case TBP soils.

Table 10: Effect of REDOX Manipulation

\begin{tabular}{lllll}
\hline & & \multicolumn{3}{c}{ Removal Increase (\%) } \\
\cline { 5 - 5 } REDOX Agent & Chelant & Copper & Lead & Zinc \\
\hline Sodium borohydride & EDTA & 0 & 1.4 & 5.7 \\
Sodium metabisulfite & EDTA & 6.3 & 0 & 13.7 \\
Sodium percarbonate & EDTA & 2.7 & 0 & 4.0 \\
& & & & \\
Sodium borohydride & Citric acid & 0 & 0 & 27.0 \\
Sodium metabisulfite & Citric acid & 0.6 & 0.5 & 20.5 \\
Sodium percarbonate & Citric acid & 0 & 2.6 & 24.8 \\
\hline
\end{tabular}

Figures $2 a, 2 b$, and $2 c$ summarize the results of soil washing/soil flushing (i.e., EDTA, citric acid) and enhancements to soil washing/soil flushing portions of this study. The results indicate that EDTA is much more effective than cirric acid for removing copper, lead, and zinc from the worst-case TBP soils. For chelant extraction with EDTA, the removal efficiencies of copper, lead, and zinc tend to plateau at values comparable to the forms present as exchangeable and carbonate species. The zinc results in Figure $2 c$ indicate that REDOX manipulation combined with chelant extraction with citric acid can be used to achieve zinc removal efficiencies comparable to those of EDTA. Depending on the method used to treat the heavy metal-containing extraction solutions, it may be desirable to use REDOX manipulation and mild chelation in place of EDTA. Because it is much more difficult to remove heavy metals from extraction solutions containing EDTA, the citrate-containing effluent will be easier to treat by conventional water treatment technologies. Treatment of the citrate-containing effluent may result in cirrate recovery and reuse.

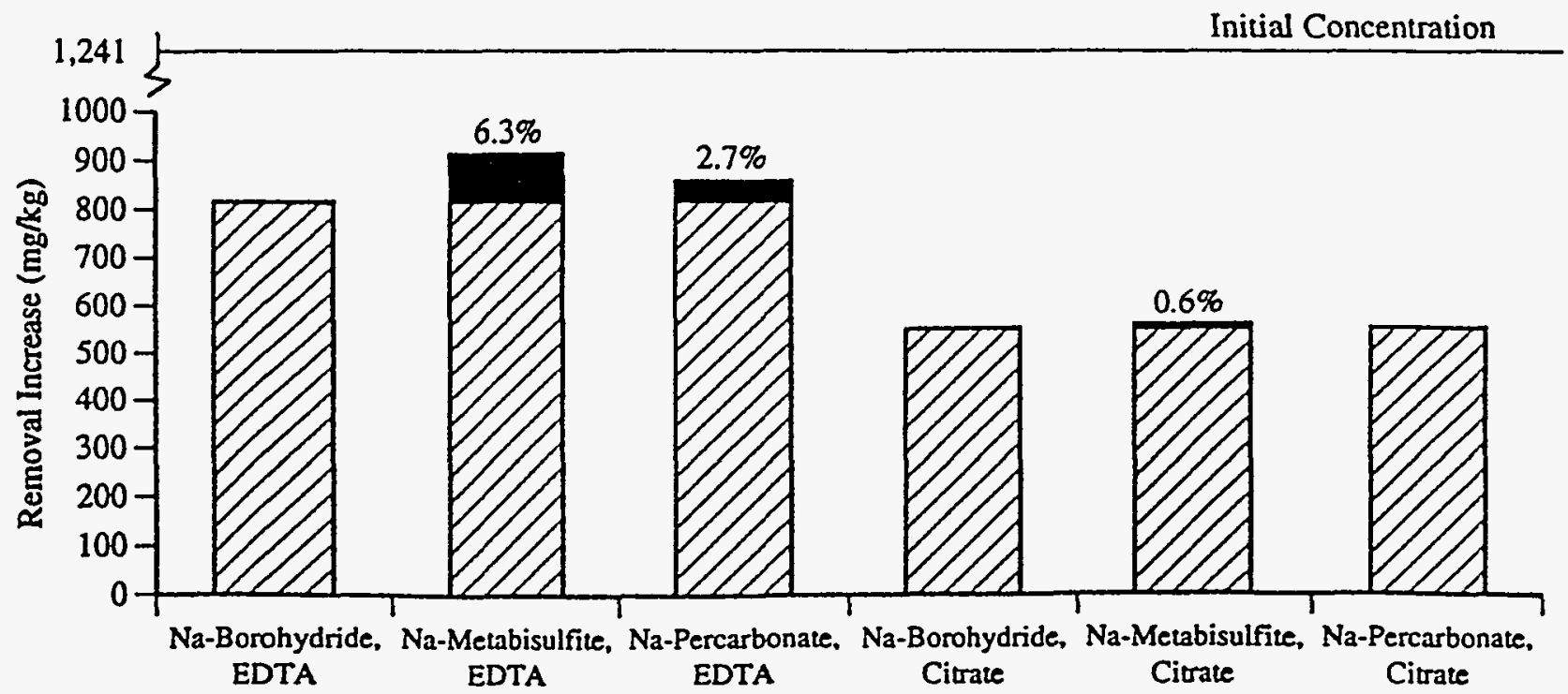

Figure 2a: Copper Removal by REDOX Manipulation and Chelant Extraction 


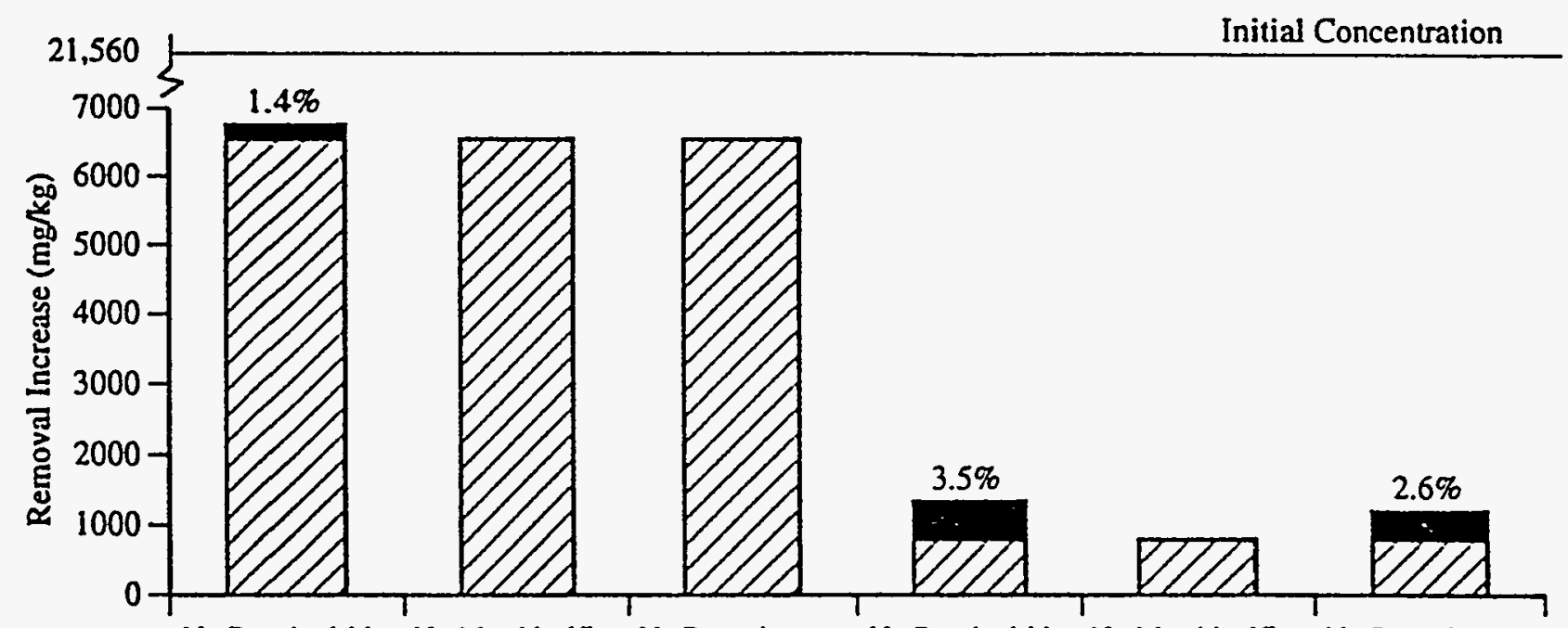

Na-Bornhydride. Na-Metabisulfite. Na-Percarbonate, Na-Borohydride. Na-Metabisulfite. Na-Percarbonate. $\begin{array}{lllll}\text { EDTA } & \text { EDTA } & \text { EDTA } & \text { Citrate } & \text { Citrate }\end{array}$

Figure 2b: Lead Removal by REDOX Manipulation and Chelant Extraction

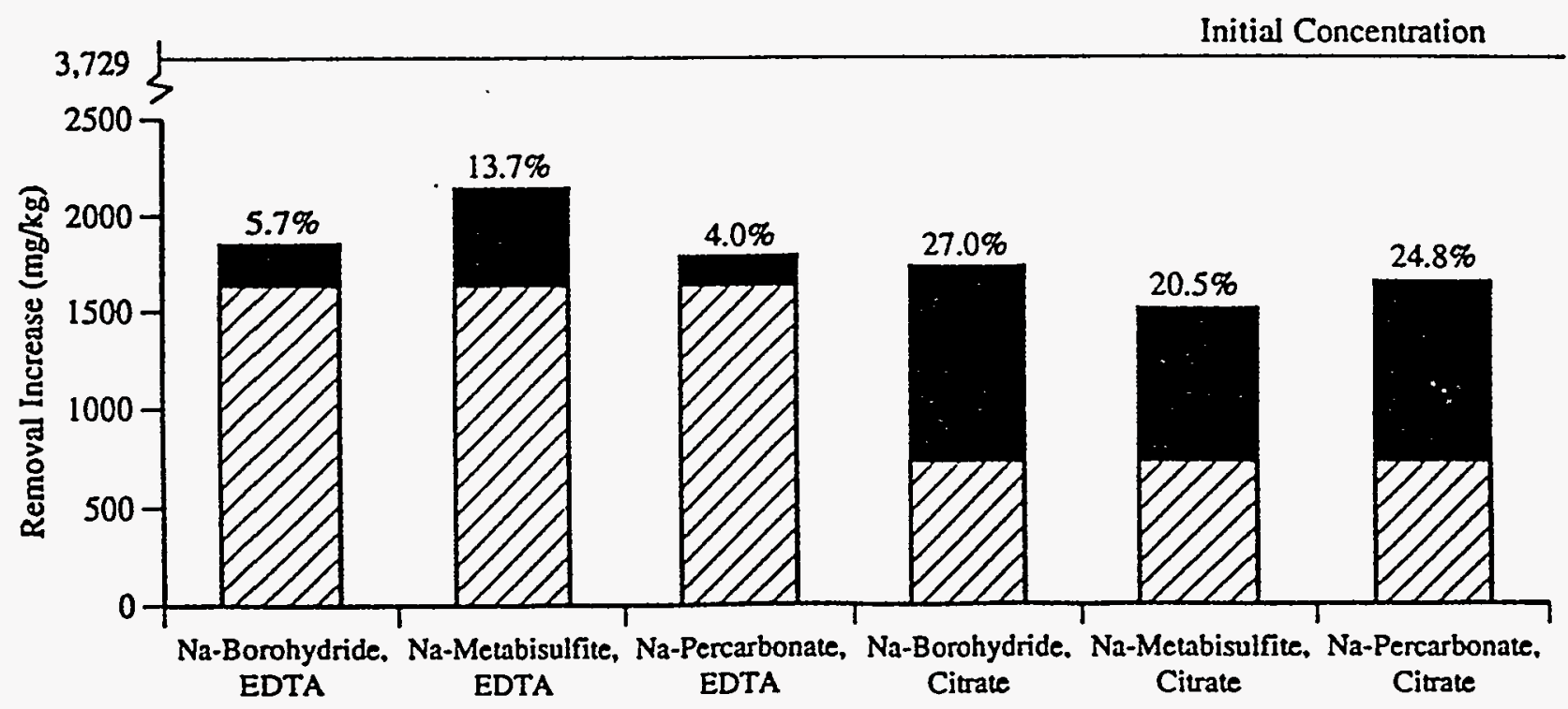

Figure 2c: Zinc Removal by REDOX Manipulation and Chelant Extraction 


\section{CONCLUSIONS}

The results from tasks 1-3 indicate that soil washing and soil flushing are effective remediation techniques for removing copper, lead, and zinc from the TBP soils. The heavy metal removal efficiencies and final residuals were dependent on the initial species of heavy metals present. Because the experiments were performed as bench-scale batch treatability tests, heavy metal removal efficiencies may have been partially restricted by the saturation of the extraction solutions. The data suggest that heavy metal extraction is limited to the quantities of heavy metals present as exchangeable and carbonate species. Depending on the type of chelant used, it was also possible to remove small portions of the reducible oxides, organometallic fractions, and residual species present in the representative TBP soil samples.

It may be feasible to use REDOX manipulation to convert metals to species that are more easily extracted. The results from the combined REDOX manipulation/chelant extraction experiments indicate that pretreatment of the TBP soils with sodium borohydride, sodium metabisulfite, and sodium percarbonate can be used to improve zinc removal efficiencies. It was demonstrated that REDOX modification may be used to pretreat soils and enable chelant extraction with citric acid to achieve zinc removal efficiencies that are comparable to chelant extraction with EDTA.

Tasks 4 and 5 will soon be completed. Once the complete set of results is received, a remedial technology will be chosen that addresses the site-specific needs of the TBP soils at J-Field.

\section{ACKNOWLEDGMENTS}

This project has been funded by the U.S. Army, Directorate of Safety, Health, and Environment. The authors acknowledge Wen Li of Argonne National Laboratory for performing the heavy metal speciation via sequential extraction experiments. The authors also greatly appreciate the outstanding analytical support provided by John D. Taylor and Laura R. Skubal in the Energy Systems Division's Soils Laboratory at Argonne National Laboratory. 